\title{
Interaction between adrenal glucocorticoids and parasympathetic activation in mediating hyperinsulinaemia during long-term central neuropeptide $\mathbf{Y}$ infusion in rats
}

\author{
A. Sainsbury, D. Wilks, G.J. Cooney \\ Diabetes Research Group, Garvan Institute of Medical Research, Darlinghurst, Sydney, Australia
}

\begin{abstract}
Aims/hypothesis. Hypothalamic neuropeptide $\mathrm{Y}$ is implicated in the aetiology of obesity and insulin resistance because of its hyperinsulinaemic, hyperphagic effects. We investigated the interaction of adrenal glucocorticoids and the parasympathetic nervous system in the hyperinsulinaemia caused by neuropeptide $\mathrm{Y}$ infusion in rats.

Methods. Neuropeptide Y was intracerebroventricularly given to normal or adrenalectomised rats for 3-6 days with pair-feeding, with or without subcutaneous dexamethasone infusion. We measured basal and intravenous glucose-induced insulinaemia and the effect of prior atropine injection.

Results. Neuropeptide Y increased basal plasma insulin and C-peptide concentrations $(380 \pm 90$ and $1000 \pm 60 \mathrm{pmol} / \mathrm{l}$, vs $190 \pm 20$ and $590 \pm 50 \mathrm{pmol} / \mathrm{l}$ in controls, $p<0.05)$. Neuropeptide $\mathrm{Y}$ also increased the plasma concentrations of these hormones as early as $60 \mathrm{~s}$ after glucose injection $(1630 \pm 170$ and $3200 \pm 170 \mathrm{pmol} / \mathrm{l}$ for insulin and $\mathrm{C}$ peptide, respectively, vs $1080 \pm 80$ and $1860 \pm 130 \mathrm{pmol} / \mathrm{l}$ in controls, $p<0.05)$. Atropine reversed the effect of neuropep-
\end{abstract}

tide Y on basal plasma insulin and C-peptide concentrations but had no effect on post-glucose plasma concentrations. The hyperinsulinaemic effects of neuropeptide $\mathrm{Y}$ were prevented by adrenalectomy, but were restored by dexamethasone infusion. Dexamethasone in itself did not statistically significantly increase insulinaemia in adrenalectomised rats. As in intact rats, atropine attenuated the basal hyperinsulinaemia of adrenalectomised rats that had been infused with neuropeptide $\mathrm{Y}$ and dexamethasone but had no effect on post-glucose hyperinsulinaemia. Conclusion/interpretation. These data suggest firstly that neuropeptide Y infused centrally induces basal hyperinsulinaemia in rats through glucocorticoid-dependant parasympathetic activation to the pancreas. Secondly, neuropeptide Y potentiates glucose-induced insulinaemia through a pathway dependant on adrenal glucocorticoids that cannot be reversed by short-term blockade of the increased parasympathetic tonus. [Diabetologia (2000) 43: 859-865]

Keywords Neuropeptide Y, intracerebroventricular, hyperinsulinaemia, adrenalectomy, atropine, dexamethasone, rat.
Neuropeptide Y (NPY) is one of several neuropeptides involved in body energy homeostasis through actions within the hypothalamus. It could contribute

Received: 11 January 2000 and in revised form: 28 February 2000

Corresponding author: Dr A. Sainsbury, Diabetes Research Group, Garvan Institute of Medical Research, 384 Victoria Street, Darlinghurst, NSW 2010, Sydney, Australia

Abbreviations: NPY, Neuropeptide Y; ICV, intracerebroventricular; ADX, adrenalectomised; DEX, dexamethasone. to the development of obesity and insulin resistance when hypothalamic concentrations remain high. High hypothalamic NPY-ergic activity has been reported in rodent genetic obesity syndromes [1-4], in which the leptin or leptin receptor gene is not functional $[5,6]$. In these rodents, the lack of leptin-mediated inhibition of NPY expression and secretion [1] is thought to be responsible for the associated increase in brain NPY expression. Although other peptides could be involved, further evidence suggests that NPY has a causative role in the aetiology of obesity 
because central infusion of exogenous NPY to normal rodents leads to defects characteristic of obesity including hyperphagia, accelerated body weight gain, hypercorticosteronaemia, hyperinsulinaemia, muscle insulin resistance and increased triglyceride storage in white adipose tissue [7-13]. These hormonal and metabolic perturbations are present even when NPY-induced hyperphagia is prevented [8, 9, 13], showing that hyperphagia is not necessary for central NPY to produce its obesity-like effects. Neuropeptide Y most probably regulates body adiposity in concert with other important hypothalamic peptides, such as agouti-related peptide, alpha melanocyte stimulating hormone and corticotropin releasing hormone [14].

Because central NPY could be involved in the pathogenesis of insulin resistance and obesity, and hyperinsulinaemia is probably a causative factor in the metabolic defects of obesity and the associated Type II (non-insulin-dependent) diabetes mellitus [15-17] and could contribute to overeating [18], we wished to understand the mechanisms by which central infusion of NPY leads to systemic hyperinsulinaemia.

It was previously shown that adrenalectomy prevented development of basal hyperinsulinaemia and the associated obese and insulin resistant syndrome induced by long-term central NPY infusion in rats $[19,20]$. Furthermore, prior vagotomy totally prevented development of the basal and substrate-induced hyperinsulinaemia caused by long-term central NPY infusion [13], indicating that central NPY increases insulinaemia in rats by activation of the vagus nerve. Because both of these procedures (adrenalectomy and vagotomy) completely block NPY-induced hyperinsulinaemia, it is possible that both interventions are acting on a common pathway.

The aim of this work was to test the hypothesis that adrenal glucocorticoids are necessary for the hyperinsulinaemic effects of central NPY because they permit NPY-induced activation of parasympathetic efferent (vagal) fibres to the pancreas. To explore this possibility, we examined the insulinaemic responses to 3-6 days of intracerebroventricular (ICV) NPY infusion in control rats, adrenalectomised rats and adrenalectomised rats that had received replacement glucocorticoid in the form of subcutaneous dexamethasone infusion. The contribution of parasympathetic activation to hyperinsulinaemia was investigated in these groups of rats by injection of atropine methyl nitrate, which blocks muscarinic receptors in the peripheral but not the central nervous system [21].

\section{Materials and methods}

Animals. Procedures were approved by the Animal Experimentation Ethics Committee of the Garvan Institute and St Vincent's Hospital and are in keeping with the National
Health and Medical Research Council of Australia's guidelines on animal experimentation. Male Wistar rats (Animal Resources Centre, Perth, Australia) were housed under conditions of controlled temperature $\left(23^{\circ} \mathrm{C}\right)$ and illumination (0600-1800 hours) on sawdust bedding. They were allowed free access to standard laboratory chow (Norco Stockfeeds, South Lismore, Australia) and water, unless otherwise stated.

Placement of long-term ICV and jugular cannulae in normal rats. At 11 weeks of age (body weight $384 \pm 3 \mathrm{~g}, n=16$ ) rats were anaesthetised with intraperitoneal ketamine and xylazine $(60 \mathrm{mg} / \mathrm{kg}$ and $10 \mathrm{mg} / \mathrm{kg}$, Parke-Davis, Australia and Bayer, Leverkusen, Switzerland) for cannulation of the right lateral cerebral ventricle [22] and jugular vein. Rats received intramuscular procaine penicillin and benzathine penicillin $(45 \mathrm{mg} / \mathrm{kg}$ and $35 \mathrm{mg} / \mathrm{kg}$, Duplocillin, Intervet, Sydney, Australia) and subcutaneous analgesic (Temgesic, $25 \mathrm{mg} / \mathrm{kg}$, Reckitt and Coleman, Hull, UK) and were left to recover pre-surgery weights (7-10 days) in individual cages, with daily handling. The drinking response to ICV injection of angiotensin II ( $25 \mathrm{ng}$ in $5 \mu \mathrm{l} \mathrm{sa-}$ line, Auspep, Melbourne, Australia) was tested. Only rats that drank approximately $8 \mathrm{mls}$ or more in the $30 \mathrm{~min}$ after injection ( $\sim 90 \%$ of the animals) were used for further studies.

Long-term ICV infusion of NPY in normal rats. At 12-13 weeks of age, rats were anaesthetised by halothane for implantation of subcutaneous osmotic minipumps (model 2001, Alza, Palo Alto, Calif., USA) for ICV infusion of porcine NPY $(15 \mu \mathrm{g} /$ day, Auspep, Melbourne, Australia) or vehicle ( $0.04 \mathrm{~mol} / \mathrm{l}$ phosphate-buffered saline, $\mathrm{pH} 7.4$, with $0.2 \%$ bovine serum albumin and $0.01 \%$ ascorbic acid) [22]. These two groups of rats were abbreviated as normal + vehicle (330 7 g) and normal + NPY (334 $\pm 6 \mathrm{~g}, n=8$ rats per group, NS). To prevent NPY-induced hyperphagia, all animals were given and consumed $32 \mathrm{~g}$ /day of chow, which is the amount they ate spontaneously before NPY infusion.

Measurement of basal and glucose-stimulated insulin and $C$ peptide plasma concentrations in normal rats. The effect of atropine methyl nitrate $(1.0 \mathrm{mg} / \mathrm{kg}$, Sigma, St Louis, Mo., USA) to block muscarinic stimulation of insulin release was verified in pilot studies $(n=6)$. Intravenous carbachol injection $(0.033 \mathrm{mg} / \mathrm{kg})$ increased insulinaemia from $290 \pm 30 \mathrm{pmol} / 1$ to $1360 \pm 160 \mathrm{pmol} / 110 \mathrm{~min}$ after injection $(p<0.001)$. This effect was prevented by bolus intravenous injection of atropine $20 \mathrm{~min}$ before the carbachol injection $(170 \pm 30 \mathrm{pmol} / \mathrm{l}$, $p<0.001$ vs carbachol, $p>0.05$ vs basal). Experiments in ICV-infused rats were commenced between 1030 and 1200 hours, 2 to $3 \mathrm{~h}$ after removal of food. After 3-4 days of ICV infusion, rats were connected to an extension cannula to enable blood sampling in the freely moving state. A basal blood sample was taken and an intravenous glucose bolus was injected $(300 \mathrm{mg} / \mathrm{kg})$, followed by removal of blood samples for $20 \mathrm{~min}$. Erythrocytes were returned to the animal. After 2 days of recovery the above procedure was repeated but atropine $(1.0 \mathrm{mg} / \mathrm{kg})$ was intravenously injected as a bolus $20 \mathrm{~min}$ before the glucose injection (normal + vehicle + atropine; normal + NPY + atropine). An additional basal sample was taken immediately before atropine injection. All plasma samples were stored at $-20^{\circ} \mathrm{C}$ until assay. Incremental areas under the insulin and C-peptide curves were calculated (by subtracting baseline values) between zero and 5 min after glucose injection and referred to as glucose-stimulated incremental insulin or C-peptide concentrations.

Experiments with adrenalectomised rats. Rats were bilaterally adrenalectomised at 10-11 weeks of age (body weight $358 \pm 3$ 
g, $n=36)$ under ketamin and xylazine anaesthesia. Rats were given a local analgesic subcutaneously (Marcaine, $5 \mathrm{mg} / \mathrm{kg}$, Astra Pharmaceuticals, North Ryde, Australia) and allowed to recover pre-surgery weights (7-10 days). Drinking water was supplemented with $0.9 \% \mathrm{NaCl}$. Long-term ICV and jugular cannulae were implanted as described for normal rats and a single dose of dexamethasone $(25 \mu \mathrm{g} / \mathrm{rat}$, Oradexon, Organon, Pfaffikon, Switzerland) was injected subcutaneously to aid recovery. Correct placement of the ICV cannula was verified as described for normal rats. Blood samples were taken 10 days after surgery and only rats with negligible plasma corticosterone concentrations $(<25 \mathrm{ng} / \mathrm{ml})$ were used. At $13-14$ weeks of age, NPY $(15 \mu \mathrm{g} /$ day $)$ or vehicle were ICV infused by osmotic minipump. Half of the rats in each group (NPY-infused or vehicle-infused) received an additional minipump for the subcutaneous infusion of dexamethasone (DEX) at $7.5 \mu \mathrm{g} \cdot \mathrm{kg}^{-1} \cdot$ day $^{-1}$. The four groups of adrenalectomised $(\mathrm{ADX})$ rats were $\mathrm{ADX}+$ vehicle $(415 \pm 13 \mathrm{~g})$; ADX + NPY $(429 \pm 16 \mathrm{~g}) ; \mathrm{ADX}+\mathrm{DEX}(398 \pm 12 \mathrm{~g}) ; \mathrm{ADX}+\mathrm{NPY}+\mathrm{DEX}$ $(412 \pm 11 \mathrm{~g}, n=4-7$ rats per group, NS). All animals were given and consumed $32 \mathrm{~g} /$ day of chow, an amount equivalent to their spontaneous food intake measured before infusion. After 3-4 days of ICV infusion, basal and glucose-stimulated insulinaemia were measured as for normal rats. After 2 days of recovery this procedure was repeated, with bolus intravenous injection of atropine methyl nitrate $(1.0 \mathrm{mg} / \mathrm{kg}) 20 \mathrm{~min}$ before glucose.

Plasma hormone and metabolite measurements. Plasma glucose concentrations were determined with the Trace Scientific (Melbourne, Australia) glucose oxidase method and plasma insulin and C-peptide concentrations were assayed with Linco Research (St Louis, Mo., USA) radioimmunoassay kits. Corticosteronaemia was measured with a radioimmunoassay kit from ICN Biomedicals (Costa Mesa, Calif., USA).

Statistical analysis. For all statistical analyses, $p$ less than 0.05 was accepted as being statistically significant. Results were assessed by one-way ANOVA, one-way ANOVA with repeated measures or by three-way ANOVA as appropriate, followed by Fisher's post-hoc tests, using StatView version 4.5 (Abacus Concepts, Calif., USA).

\section{Results}

Effect of muscarinic blockade on NPY-induced hyperinsulinaemia in normal rats. Basal plasma concentrations of insulin and C-peptide were significantly increased in normal rats infused ICV with NPY for 36 days (pair-fed with controls) compared with normal control rats (Fig. 1). These NPY-induced increases returned to normal $20 \mathrm{~min}$ after intravenous atropine injection. Atropine itself did not affect the basal plasma insulin and C-peptide concentrations of normal rats infused with vehicle (Fig. 1). There was no difference in glycaemia between normal + vehicle and normal + NPY-infused rats (Table 1) nor did atropine have any effect on the basal glycaemia of these rats (data not shown).

Increases in plasma insulin and C-peptide concentrations elicited by intravenous glucose injection in normal rats were further significantly increased by
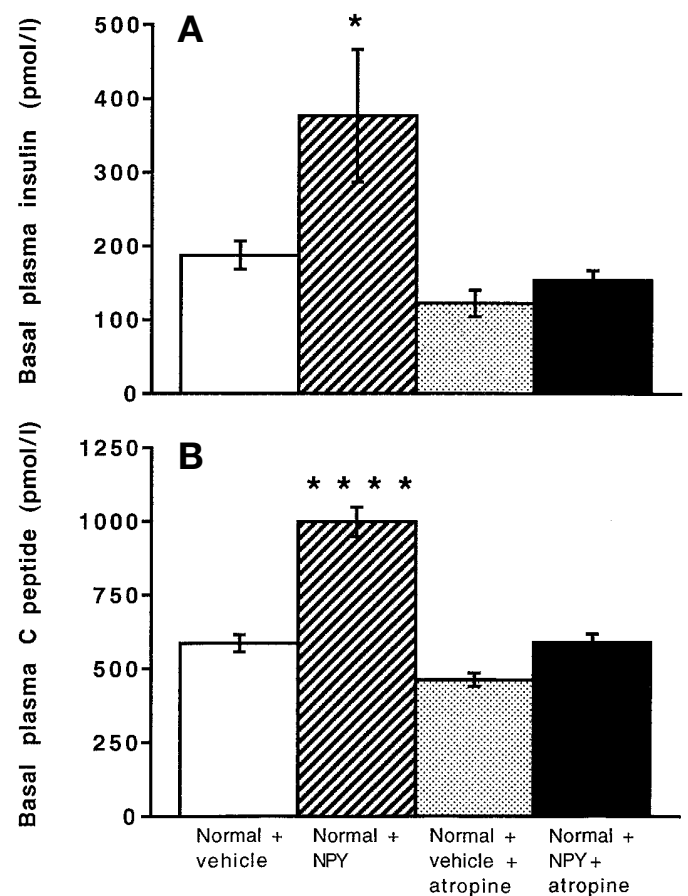

Fig. 1A, B. Basal plasma insulin (A) and C-peptide concentrations (B) in normal rats ICV infused with vehicle or NPY (15 $\mu \mathrm{g} /$ day for 3-6 days); effect of atropine $(1.0 \mathrm{mg} / \mathrm{kg}$ i. v. $)$, injected $20 \mathrm{~min}$ before basal blood sampling. To prevent NPYinduced hyperphagia, animals were fed an amount equivalent to their spontaneous food intake before infusion. Plotted values are means \pm SEM of $4-6$ rats per group. $* p<0.05$; $* * * * p<0.0001$ vs normal + vehicle (one-way ANOVA with repeated measures, followed by post-hoc tests)

NPY infusion for 3-6 days in rats pair-fed with vehicle-infused control rats (Fig. 2). This NPY-induced increase reached statistical significance as early as 1 min after glucose injection ( $p<0.05$ vs normal + vehicle). There was no difference in glycaemia between normal + vehicle and normal + NPY rats after glucose injection (Table 1). The incremental areas under the curves from Fig. 2 were calculated between 0-5 min (Table 2) and were significantly greater in NPY-infused than in vehicle-infused control rats. Atropine, injected $20 \mathrm{~min}$ before glucose, did not reduce the enhanced incremental insulin and C-peptide concentrations measured in normal + NPY-infused rats nor did it affect the glucose-induced concentrations of either insulin or $\mathrm{C}$ peptide in normal + vehicle-infused rats. Atropine had no effect on glycaemia after glucose injection in normal + vehicle and normal + NPY rats (data not shown).

Effects of glucocorticoid replacement and muscarinic blockade on NPY-induced changes in insulinaemia in adrenalectomised rats. There was no significant difference in basal or stimulated glucose concentrations among the four groups of adrenalectomised rats used in these experiments (Table 1). Figure 3 illustrates the effects of 3-6 day ICV NPY infusion in 
Table 1. Plasma glucose concentrations measured basally, as well as 1 and 5 min after intravenous glucose injection (300 $\mathrm{mg} / \mathrm{kg})$

\begin{tabular}{llll}
\hline Treatment & $\begin{array}{l}\text { Basal } \\
(\mathrm{mmol} / \mathrm{l})\end{array}$ & $\begin{array}{l}\text { 1 min after } \\
\text { glucose } \\
(\mathrm{mmol} / \mathrm{l})\end{array}$ & $\begin{array}{l}5 \text { min after } \\
\text { glucose } \\
(\mathrm{mmol} / \mathrm{l})\end{array}$ \\
\hline Normal + vehicle & $7.4 \pm 0.5$ & $20.2 \pm 0.6$ & $10.9 \pm 0.3$ \\
Normal + NPY & $7.5 \pm 0.8$ & $19.6 \pm 0.4$ & $12.2 \pm 1.1$ \\
ADX + vehicle & $7.0 \pm 0.2$ & $20.0 \pm 0.9$ & $13.6 \pm 1.0$ \\
ADX + NPY & $6.6 \pm 0.4$ & $17.6 \pm 1.5$ & $11.7 \pm 0.3$ \\
ADX + DEX & $6.8 \pm 0.3$ & $20.4 \pm 1.2$ & $11.0 \pm 0.8$ \\
ADX + NPY + DEX & $6.5 \pm 0.2$ & $19.6 \pm 1.0$ & $13.3 \pm 0.6$ \\
\hline
\end{tabular}

Values are means \pm SEM of 4-8 rats per group. No significant differences between treatment groups in each category of glycaemia

Table 2. Effect of ICV NPY infusion for 3-6 days $(15 \mu \mathrm{g} /$ day $)$ on glucose-stimulated incremental insulin and C-peptide concentrations in normal rats and effect of atropine $(1.0 \mathrm{mg} / \mathrm{kg}$ i.v.)

\begin{tabular}{lll}
\hline Treatment & $\begin{array}{l}\text { Insulin } \\
\text { increment } \\
\left(\mathrm{pmol} / \mathrm{l} \times 0-5^{\prime \prime}\right)\end{array}$ & $\begin{array}{l}\text { C-peptide } \\
\text { increment } \\
\left(\mathrm{pmol} / 1 \times 0-5^{\prime \prime}\right)\end{array}$ \\
\hline Normal + vehicle & $2,820 \pm 90$ & $4,930 \pm 300$ \\
Normal + vehicle + atropine & $2,300 \pm 160$ & $4,080 \pm 170$ \\
Normal + NPY & $4,450 \pm 660^{\mathrm{a}}$ & $7,170 \pm 530^{\mathrm{b}}$ \\
Normal + NPY + atropine & $4,160 \pm 240^{\mathrm{a}}$ & $7,540 \pm 1030^{\mathrm{b}}$ \\
\hline
\end{tabular}

Values are means \pm SEM of $4-6$ rats per group. ${ }^{a} p<0.05$; ${ }^{\mathrm{b}} p<0.01$ vs normal + vehicle group

adrenalectomised rats (either with or without concomitant subcutaneous infusion of dexamethasone) on basal insulinaemia and on glucose-stimulated incremental insulin concentrations. Whereas giving NPY to normal rats resulted in a significant basal hyperinsulinaemia (Fig.1) and an increase in glucoseinduced insulin concentrations (Fig. 2, Table 2), these effects of NPY were totally prevented by prior adrenalectomy (ADX + NPY, Fig. 3). Supplementing adrenalectomised rats with subcutaneous dexamethasone for 3-6 days restored, however, the ability of NPY to induce basal and glucose-induced hyperinsulinaemia (ADX + NPY $+\mathrm{DEX})$ relative to ADX + vehicle rats (Fig. 3). Atropine attenuated the basal hyperinsulinaemia of ADX + NPY + DEX rats to levels that were similar to $\mathrm{ADX}+\mathrm{DEX}$ rats (Fig.3). Atropine had no effect on the basal insulinaemia of any other group of rats (data not shown). Although there was a tendency towards a decrease, atropine did not significantly reduce the enhanced glucose-induced integrated insulin concentrations of ADX + NPY + DEX rats (Fig. 3), or affect any of the other groups of animals (data not shown).
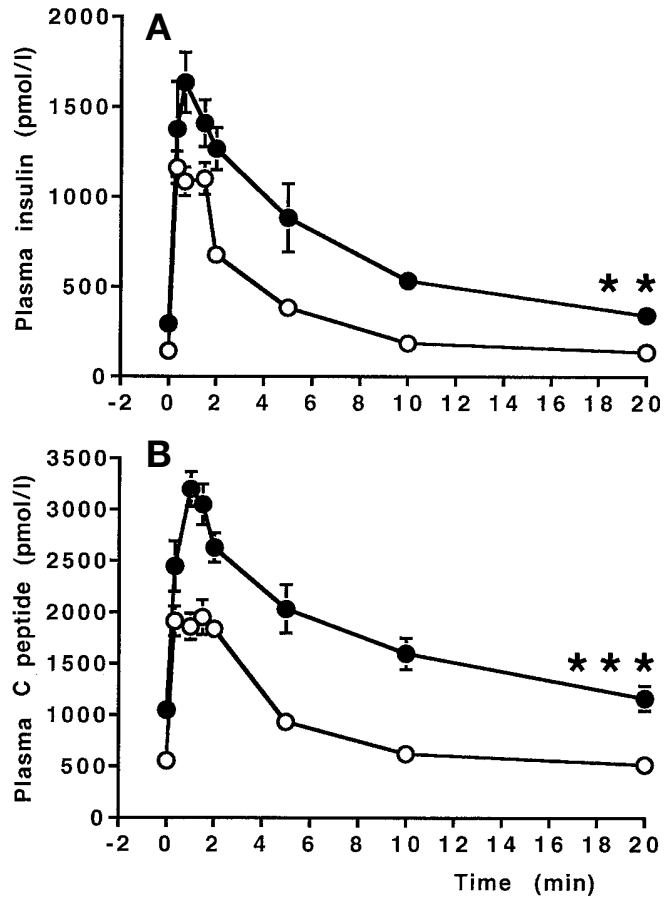

Fig. 2 A, B. Plasma insulin (A) and C-peptide (B) concentrations after bolus injection of glucose $(300 \mathrm{mg} / \mathrm{kg}$ i.v. $)$ at time zero in normal rats ICV infused with NPY $(15 \mu \mathrm{g} /$ day for 3-6 days, $)$ ) and pair-fed with vehicle-infused controls $(\bigcirc)$ to prevent NPY-induced hyperphagia. Plotted values are means \pm SEM of $5-6$ rats per group. $* * p<0.001$; $* * * p<0.0001$ compared with curve for normal + vehicle group (one-way ANOVA with repeated measures)

\section{Discussion}

The aim of this work was to study the interaction between adrenal glucocorticoids and the parasympathetic nervous system in mediating hyperinsulinaemia during long-term central (ICV) NPY infusion in rats. Our principal findings were that NPY-induced basal hyperinsulinaemia was prevented by adrenalectomy, was restored by glucocorticoid supplementation and could be subsequently reversed by shortterm parasympathetic blockade with atropine. The results suggest that adrenal glucocorticoids and parasympathetic activation work in concert to mediate hyperinsulinaemia during central NPY infusion.

It was reported previously $[9,10,13]$ that ICV NPY infusion for several days in normal rats (pairfed with controls to prevent NPY-induced hyperphagia) increased basal insulinaemia. Such hyperinsulinaemia could be mediated by an increase in insulin secretion or a decrease in insulin clearance or both. Insulin clearance is known to be altered in states of insulin resistance in man [23] and could conceivably be perturbed by central NPY infusion, which causes muscle insulin resistance in rats [11-13]. For these reasons, we also measured plasma concentrations of $\mathrm{C}$ peptide, which offer a more accurate index of beta-cell output than insulinaemia [24]. That basal 


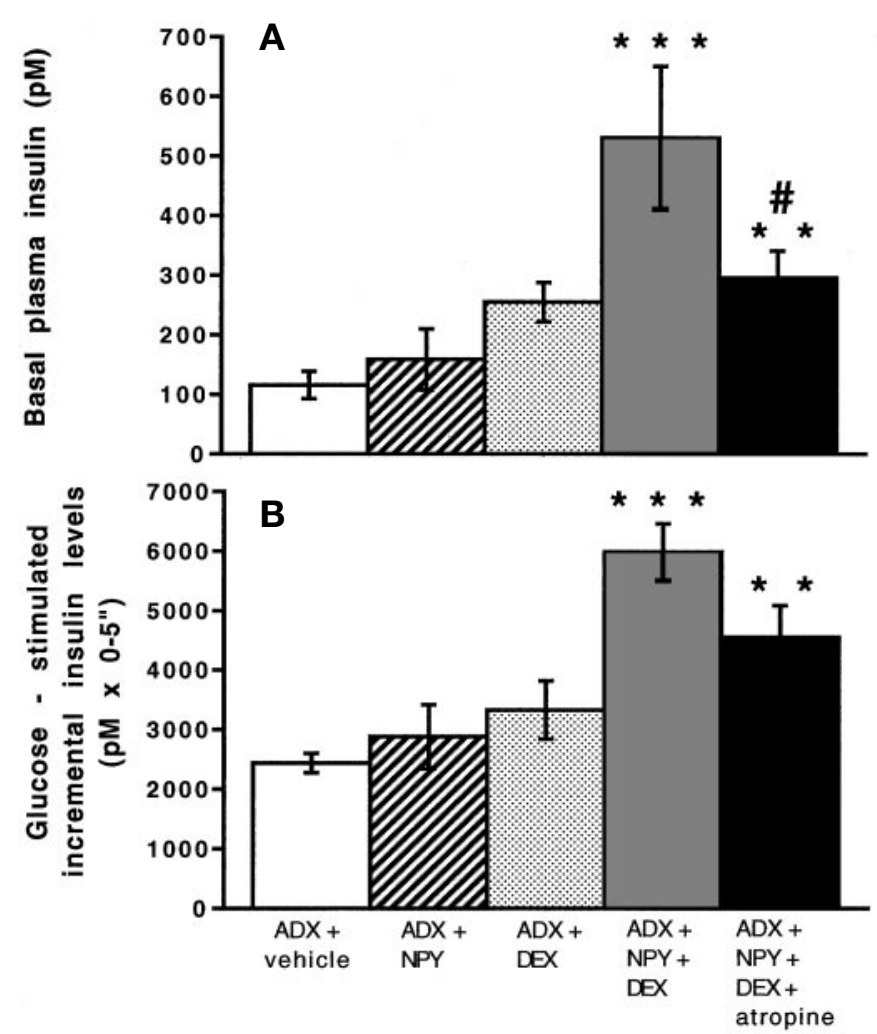

Fig. 3 A, B. Basal plasma insulin concentrations (A) and intravenous glucose-stimulated $(300 \mathrm{mg} / \mathrm{kg})$ incremental insulin concentrations $(\mathbf{B})$ in adrenalectomised (ADX) rats ICV infused with vehicle or NPY $(15 \mu \mathrm{g} /$ day for 3-6 days $) \pm$ concomitant subcutaneous dexamethasone (DEX) infusion $(7.5 \mu \mathrm{g}$. $\mathrm{kg}^{-1} \cdot$ day $\left.^{-1}\right)$; effect of atropine $(1.0 \mathrm{mg} / \mathrm{kg}$ i. v. $)$, injected $20 \mathrm{~min}$ before basal blood sampling or glucose injection. All animals were fed the same amount, which was equivalent to their spontaneous food intake before infusion. Plotted values are means \pm SEM of $4-8$ rats per group. $* * p<0.01 ; * * * p<0.0001$ vs ADX + vehicle group. \# $p<0.005$ vs $\mathrm{ADX}+\mathrm{NPY}+\mathrm{DEX}$ group (three-way ANOVA, followed by post-hoc tests)

C-peptide concentrations were also increased by ICV NPY infusion in this study suggests that central NPY stimulates basal insulin secretion.

The NPY-induced increases in basal plasma insulin and C-peptide concentrations, once established, returned completely to normal 20 min after short-term parasympathetic muscarinic blockade with atropine. In support of our data, long-term vagotomy has been shown to prevent the development of NPY-induced basal hyperinsulinaemia in rats [13]. This collectively suggests that central NPY initiates and maintains increased basal insulin output by a continuous increase in vagal, muscarinic tonus in the pancreas.

It is most likely that NPY increases actual parasympathetic output to the pancreas, because the hyperinsulinaemic effect of NPY is only observed after central but not after intravenous infusion [25] or in vitro application [26, 27]. Furthermore, other gastrointestinal effects of central NPY infusion can be prevented by vagotomy or atropine [28], consistent with an NPY-induced increase in parasympathetic output to the gastrointestinal tract by a central effector site.

Our data show that several days of central NPY infusion in normal rats potentiates the secretion of insulin and $\mathrm{C}$ peptide in response to glucose stimulation. Previous reports showed that long-term ICV NPY infusion in normal rats potentiated insulinaemia measured at about 2 min [10] and the incremental, integrated insulin response between 0 and $60 \mathrm{~min}$ after glucose injection [13]. The contribution of possible NPY-induced changes in insulin clearance to these increases in insulinaemia could not, however, be discounted. In this study, the incremental increase in plasma insulin and C-peptide concentrations were enhanced as early as $60 \mathrm{~s}$ after glucose injection in NPY-infused compared with vehicle-infused normal rats and we conclude that central NPY potentiates secretion of beta-cell insulin products in response to intravenous glucose injection.

Once glucose-induced insulin hypersecretion had been established by several days of central NPY infusion, it could not be reversed by short-term parasympathetic, muscarinic blockade, indicating that it was mediated by different mechanisms to those eliciting basal hyperinsulinaemia. One possible explanation is that exposure of pancreatic islets to high parasympathetic tonus during ICV NPY infusion primes the beta cells to glucose stimulation, even after parasympathetic input has been abolished by atropine. Such carbachol-induced glucose sensitisation has been shown in isolated islets for up to $45 \mathrm{~min}$ after removal of cholinergic agonists from the perifusion medium [29]. This mechanism is also consistent with a previous finding that bilateral vagotomy before long-term ICV NPY infusion in rats was able to prevent development of the exaggerated insulinaemic response to glucose [13], showing involvement of the parasympathetic system in development of this NPY effect. Similarly, atropine when given to adult obese $f a / f a$ rats was unable to completely return the enhanced glucose-mediated insulin secretion, characteristic of these rats, to normal $[30,31]$ but did completely reverse this defect when given to preweaning $f a / f a$ pups [31, 32], in which long-term defects leading to glucose hyperresponsiveness, such as increased betacell mass, are not yet observed $[33,34]$.

Our results show that the stimulatory effects of NPY on basal and glucose-induced insulinaemia were both absent in adrenalectomised rats and were restored by subcutaneous dexamethasone infusion. In support of the necessary role of adrenal glucocorticoids in NPY-induced hyperinsulinaemia, the basal hyperinsulinaemia in NPY-infused rats has shown a similar and selective dependence on adrenal glucocorticoids $[19,20]$.

We have tested the hypothesis that adrenal glucocorticoids are necessary for the parasympathetically mediated hyperinsulinaemia induced by long-term 
central NPY infusion in rats. We showed that shortterm muscarinic blockade with atropine statistically significantly attenuated the basal hyperinsulinaemia of adrenalectomised rats that had been infused with central NPY and peripheral glucocorticoids for several days. This shows that the basal hyperinsulinaemia of these rats involved a glucocorticoid-dependent increase in parasympathetic, muscarinic tonus in the endocrine pancreas. Basal hyperinsulinaemia induced by NPY seems to occur by the same mechanism as that shown in genetically obese fa/fa rats. Hyperinsulinaemia in $f a / f a$ rats can be prevented by preweaning adrenalectomy but was restored by $24-\mathrm{h}$ peripheral replacement corticosterone and was restored to normal by atropine [35].

Available evidence suggests that glucocorticoids were acting centrally to permit the hyperinsulinaemic effects of NPY in adrenalectomised rats. That NPY-induced basal hyperinsulinaemia was antagonised by atropine would suggest that dexamethasone (type II adrenal steroid receptor agonist) was acting in concert with NPY within the central nervous system to activate parasympathetic efferent fibres. Type II adrenal steroid receptor immunoreactivity and mRNA have been detected within the brain, including areas anatomically linked to the vagus nerve such as the lateral and ventromedial hypothalamic nuclei [36-39]. These areas show expression of various NPY receptor subtypes [40] and could thus be involved in glucocorticoid regulation of NPY's effects on insulin output.

These data collectively suggest that NPY infused centrally induces sustained basal hyperinsulinaemia in rats by continuously increased parasympathetic activity in the pancreas and this effect is dependent on adrenal glucocorticoids, possibly acting within the brain. Adrenal glucocorticoids are also necessary for the potentiation of glucose-induced insulinaemia by long-term central NPY infusion but this effect cannot be reversed by short-term blockade of the increased parasympathetic output.

Acknowledgements. The National Health and Medical Research Council of Australia has supported this work through a centre grant to the Garvan Institute and a post-doctoral fellowship awarded to A. Sainsbury (Peter Doherty Fellowship 987122). We thank K. Bonner and L. Croft for expert assistance. Helpful discussions with Dr K. Zakrzewska, Dr I. Cusin (University of Geneva, Switzerland), Professor E.W. Kraegen and Dr A. Thompson (Garvan Institute, Sydney, Australia) were greatly appreciated. We thank Dr J. Ferguson and Dr J. Kingham for their invaluable veterinary advice, and the staff of the Garvan Institute Biological Testing Facility.

\section{References}

1. Stephens TW, Basinski M, Bristow PK et al. (1995) The role of neuropeptide $\mathrm{Y}$ in the antiobesity action of the obese gene product. Nature 377: 530-532
2. Bchini-Hooft van Huijsduijnen O, Rohner-Jeanrenaud F, Jeanrenaud B (1993) Hypothalamic neuropeptide Y messenger ribonucleic acid levels in pre-obese and genetically obese (fa/fa) rats; potential regulation thereof by corticotropin-releasing factor. J Neuroendocrinol 5: 381-386

3. Williams G, Shellard L, Lewis DE et al. (1992) Hypothalamic neuropeptide $\mathrm{Y}$ disturbances in the obese (cp/ cp)JCR:LA corpulent rat. Peptides 13: 537-540

4. Dryden S, Pickavance L, Frankish HM, Williams G (1995) Increased neuropeptide Y secretion in the hypothalamic paraventricular nucleus of obese (fa/fa) Zucker rats. Brain Res 690: 185-188

5. Zhang Y, Proenca R, Maffei M, Barone M, Leopold L, Friedman JM (1994) Positional cloning of the mouse obese gene and its human homologue. Nature 372: 425-432

6. Chen H, Charlat O, Tartaglia LA et al. (1996) Evidence that the diabetes gene encodes the leptin receptor: identification of a mutation in the leptin receptor gene in $d b / d b$ mice. Cell 84: 491-495

7. Stanley BG, Anderson KC, Grayson MH, Leibowitz SF (1989) Repeated hypothalamic stimulation with neuropeptide $\mathrm{Y}$ increases daily carbohydrate and fat intake and body weight gain in female rats. Physiol Behav 46: 173-177

8. Billington CJ, Briggs JE, Harker S, Grace M, Levine AS (1994) Neuropeptide Y in hypothalamic paraventricular nucleus: a center coordinating energy metabolism. Am J Physiol 266: R1765-R1770

9. Zarjevski N, Cusin I, Vettor R, Rohner-Jeanrenaud F, Jeanrenaud B (1993) Chronic intracerebroventricular neuropeptide-Y administration to normal rats mimics hormonal and metabolic changes of obesity. Endocrinology 133: $1753-1758$

10. Sainsbury A, Cusin I, Doyle P, Rohner-Jeanrenaud F, Jeanrenaud B (1996) Intracerebroventricular administration of neuropeptide $Y$ to normal rats increases obese gene expression in white adipose tissue. Diabetologia 39: 353-356

11. Vettor R, Zarjevski N, Cusin I, Rohner-Jeanrenaud F, Jeanrenaud B (1994) Induction and reversibility of an obesity syndrome by intracerebroventricular neuropeptide Y administration to normal rats. Diabetologia 37: 1202-1208

12. Zarjevski N, Cusin I, Vettor R, Rohner-Jeanrenaud F, Jeanrenaud B (1994) Intracerebroventricular administration of neuropeptide $\mathrm{Y}$ to normal rats has divergent effects on glucose utilization by adipose tissue and skeletal muscle. Diabetes 43: 764-769

13. Sainsbury A, Rohner-Jeanrenaud F, Cusin I et al. (1997) Chronic central neuropeptide $\mathrm{Y}$ infusion in normal rats - status of the hypothalamo-pituitary-adrenal axis, and vagal mediation of hyperinsulinaemia. Diabetologia 40: 1269-1277

14. Kalra SP, Dube MG, Pu SY, Xu B, Horvath TL, Kalra PS (1999) Interacting appetite-regulating pathways in the hypothalamic regulation of body weight. Endocr Rev 20: 68-100

15. Cusin I, Terrettaz J, Rohner-Jeanrenaud F, Zarjevski N, Assimacopoulos-Jeannet F, Jeanrenaud B (1990) Hyperinsulinemia increases the amount of GLUT4 mRNA in white adipose tissue and decreases that of muscles: a clue for increased fat depot and insulin resistance. Endocrinology 127: $3246-3248$

16. Pontiroli AE, Alberetto M, Pozza G (1992) Patients with insulinoma show insulin resistance in the absence of arterial hypertension. Diabetologia 35: 294-295

17. Marangou AG, Weber KM, Boston RC et al. (1986) Metabolic consequences of prolonged hyperinsulinemia in humans. Evidence for induction of insulin insensitivity. Diabetes 35: 1383-1389 
18. Ludwig DS, Majzoub JA, Al-Zahrani A, Dallal GE, Blanco I, Roberts SB (1999) High glycemic index foods, overeating, and obesity. Pediatrics 103: E261-E266

19. Sainsbury A, Cusin I, Rohner-Jeanrenaud F, Jeanrenaud B (1997) Adrenalectomy prevents the obesity syndrome produced by chronic central neuropeptide $\mathrm{Y}$ infusion in normal rats. Diabetes 46: 209-214

20. Zakrzewska KE, Sainsbury A, Cusin I, Rouru J, Jeanrenaud B, Rohner-Jeanrenaud F (1999) Selective dependence of intracerebroventricular neuropeptide Y-elicited effects on central glucocorticoids. Endocrinology 140: 3183-3187

21. Brezenoff HE, Xiao YF, Vargas H (1988) A comparison of the central and peripheral antimuscarinic effects of atropine and methylatropine injected systemically into the cerebral ventricles. Life Sci 42: 905-911

22. Rohner-Jeanrenaud F, Walker CD, Greco-Perotto R, Jeanrenaud B (1989) Central corticotropin-releasing factor administration prevents the excessive body weight gain of genetically obese (fa/fa) rats. Endocrinology 124: 733-739

23. Jones CN, Pei D, Staris P, Polonsky KS, Chen YD, Reaven GM (1997) Alterations in the glucose-stimulated insulin secretory dose-response curve and in insulin clearance in nondiabetic insulin-resistant individuals. J Clin Endocrinol Metab 82: 1834-1838

24. Polonsky KS, Rubenstein AH (1984) C-peptide as a measure of the secretion and hepatic extraction of insulin. Pitfalls and limitations. Diabetes 33: 486-494

25. Pettersson M, Ahrén B (1990) Insulin secretion in rats: effects of neuropeptide $\mathrm{Y}$ and noradrenaline. Diabetes Res 13: $35-42$

26. Alwmark A, Ahrén B (1987) Phentolamine reverses NPYinduced inhibition of insulin secretion in isolated rat islets. Eur J Pharmacol 135: 307-311

27. Opara EC, Burch WM, Taylor IL, Akwari OE (1991) Pancreatic hormone response to neuropeptide Y (NPY) perifusion in vitro. Regul Pept 34: 225-233

28. Yoneda M, Tamasawa N, Takebe K et al. (1995) Central neuropeptide $\mathrm{Y}$ enhances bile secretion through vagal and muscarinic but not nitric oxide pathways in rats. Peptides 16: 727-732

29. Zawalich WS, Zawalich KC, Rasmussen H (1989) Cholinergic agonists prime the beta-cell to glucose stimulation. Endocrinology 125: 2400-2406
30. Stubbs M, York DA (1991) Central glucocorticoid regulation of parasympathetic drive to pancreatic beta-cells in the obese fa/fa rat. Int J Obesity 15: 547-553

31. Rohner-Jeanrenaud F, Hochstrasser AC, Jeanrenaud B (1983) Hyperinsulinemia of preobese and obese fa/fa rats is partly vagus nerve mediated. Am J Physiol 244: E317-E322

32. Rohner-Jeanrenaud F, Jeanrenaud B (1985) Involvement of the cholinergic system in insulin and glucagon oversecretion of genetic preobesity. Endocrinology 116: 830-834

33. Larsson LI, Boder GB, Shaw WN (1977) Changes in the islets of langerhans in the obese Zucker rat. Lab Invest 36: 593-598

34. Cockburn BN, Ostrega DM, Sturis J, Kubstrup C, Polonsky KS, Bell GI (1997) Changes in pancreatic islet glucokinase and hexokinase activities with increasing age, obesity, and the onset of diabetes. Diabetes 46: 1434-1439

35. Fletcher JM, McKenzie N (1988) The parasympathetic nervous system and glucocorticoid-mediated hyperinsulinaemia in the genetically obese (fa/fa) Zucker rat. J Endocrinol 118: 87-92

36. Morimoto M, Morita N, Ozawa H, Yokoyama K, Kawata M (1996) Distribution of glucocorticoid receptor immunoreactivity and mRNA in the rat brain: an immunohistochemical and in situ hybridization study. Neurosci Res 26: 235-269

37. Harfstrand A, Cintra A, Fuxe K et al. (1989) Regional differences in glucocorticoid receptor immunoreactivity among neuropeptide $\mathrm{Y}$ immunoreactive neurons of the rat brain. Acta Physiol Scand 135: 3-9

38. Rohner-Jeanrenaud F (1995) A neuroendocrine reappraisal of the dual-centre hypothesis: its implications for obesity and insulin resistance. Int J Obesity 19: 517-534

39. Weaver FC (1980) Localization of parasympathetic preganglionic cell bodies innervating the pancreas within the vagal nucleus and nucleus ambiguus of the rat brain stem: evidence of dual innervation based on the retrograde axonal transport of horseradish peroxidase. J Auton Nerv Syst 2: 61-69

40. Parker RM, Herzog H (1999) Regional distribution of Yreceptor subtype mRNAs in rat brain. Eur J Neurosci 11: 1431-1448 